\title{
ARTIKKELIT
}

\section{Folkhälsans seniorboende och aktivt åldrande - BoAktiv-studien}

\author{
Anna-Maria Lahti ${ }^{1}$, Nina Simonsen ${ }^{1,2}$, Marjaana Seppänen ${ }^{3}$, Maria Finne $^{1}$, \\ Anneli Sarvimäki ${ }^{4}$, Mikaela B. von Bonsdorff ${ }^{1,5}$ \\ ${ }^{1}$ Folkhälsans forskningscentrum \\ ${ }^{2}$ Helsingfors universitet, avdelningen for folkhälsovetenskap \\ ${ }^{3}$ Helsingfors universitet, statsvetenskapliga fakulteten, socialt arbete \\ ${ }^{4}$ Äldreinstitutet \\ 5yväskylä Universitet, Gerontologian tutkimuskeskus och Idrottsvetenskapliga fakultet
}

\begin{abstract}
Syftet med denna enkätstudie var att utreda sambanden mellan social gemenskap, socialt deltagande och aktivt åldrande bland äldre personer som bor i seniorhus, samt dessa faktorers möjliga samband med hälsorelaterad livskvalitet och depressionssymptom. Syftet var också att framställa beskrivande information om hälsa och välbefinnande hos invånare i seniorhus. Målgruppen var självständigt boende i Folkhälsans seniorhus. Största delen av respondenterna var över 80 år gamla, kvinnor, svenskspråkiga och bodde ensamma. De mest aktiva seniorerna hade bättre hälsorelaterad livskvalitet samt mindre symptom av depression, och deltog mer i verksamheten i seniorhuset och hade en högre känsla av samhörighet. Respondenternas känsla av samhörighet korrelerade positivt med mental hälsa, vitalitet och energinivå. Socialt deltagande hade ett positivt samband med mental hälsa. På basis av resultaten kan man konstatera att det finns ett samband mellan aktivt åldrande, social gemenskap och socialt deltagande bland invånare i seniorhus. Det är viktigt att sträva till att öka möjligheterna till att vara aktiv och delaktig i seniorhus, vilket även kan öka känslan av samhörighet. Seniorhus har utmärkta möjligheter att mångsidigt stöda den äldres välmående.
\end{abstract}

\section{Inledning}

En femtedel av Finlands befolkning är för närvarande över 65 år, och fram till år 2030 kommer andelen enligt Statistikcentralens beräk- ningar att stiga till 26 procent, med andra ord cirka 1,5 miljoner personer. Miljöministeriet (2013) bedömer att det härmed finns ett behov av en miljon bostäder anpassade för äldre. Enligt undersökningen FinHälsa (2018) 
kan funktionsförmågans positiva utveckling inom populationen ha kommit till en vändpunkt. Rörelsesvårigheter är fortfarande relativt allmänna och befolkningens stigande ålder kommer att ytterligare öka förekomsten av dessa svårigheter. Problem i funktionsförmågan ökar i högre takt med stigande ålder, mera bland kvinnor än bland män (Sainio ym. 2018). Gruppen äldre är ändå mångfaldig och det finns anmärkningsvärda skillnader mellan de olika åldersgrupperna (Smith, Borchelt, Maier \& Jopp 2002). Bland dem som fyllt 80 år har relativt många fortfarande en god funktionsförmåga, då nästan hälften rapporterar sig kunna gå en våning upp i trappor utan besvär (Sainio ym. 2018). Att stärka funktionsförmågan och förmågan att klara sig självständigt är också ett av syftena i Äldreomsorgslagen (980/2012) där det stiftas att den långvariga vården $\mathrm{i}$ första hand skall ges $\mathrm{i}$ det egna hemmet, alltså genom att tjänsterna ordnas i hemmet. På grund av gruppens heterogenitet är det viktigt att det erbjuds olika typer av boendemöjligheter. Därmed finns det även behov av möjlighet till seniorboende. Seniorboende innebär självständigt boende i privatägd, hyres- eller bostadsrättsbostad som är tillgänglighetsanpassad, men i övrigt en vanlig bostad avsedd för personer över en viss ålder (Mikkola \& Rasila 2006). Åldersgränsen för dessa bostäder är ofta 55 år. Vanligen flyttar man in i en seniorbostad då ens eget eller partnerns hälsotillstånd är nedsatt eller det har blivit för mödosamt att upprätthålla den tidigare bostaden. Andra orsaker kan vara brist på tjänster och service i närområdet, men också ensamhet eller otrygghet (Laurinkari, Poutanen, Saarinen \& Laukkanen 2005).

Som bäst kan boendemiljön och tillgänglig service öka möjligheterna för social samvaro samt främja social gemenskap och därmed stödja aktivt åldrande (Tyvimaa 2011; Nathan, Wood \& Giles-Corti 2014). Aktivt åldrande är enligt världshälsoorganisationen WHO en process där man skapar de bästa möjligheterna till hälsa, delaktighet och trygghet i syfte att förbättra livskvaliteten hos människor som blir äldre. Aktivitet betyder inte endast fysisk aktivitet utan även deltagande i socialt liv och t.ex. i kultur (WHO 2002). Rantanen m.fl. (2018) definierar aktivt åldrande som individens strävan till aktivitet utifrån egna mål, förmågor och möjligheter. Syftet med aktivt åldrande är att möjliggöra människans fysiska, sociala och psykiska välbefinnande samt deltagande i socialt liv även som äldre (Rossi, Boccacin, Bramanti, Meda 2014). Man har funnit könsoch åldersskillnader inom aktivt åldrande. De yngre seniorerna är aktivare än de äldre seniorerna. Bland de äldre seniorerna har man funnit att män är aktivare än kvinnor (Sousa m.fl. 2018). Enligt WHO (2002) är social delaktighet i nyckelroll för aktivt åldrande. Social delaktighet och aktivitet står i samband med bättre livskvalitet (Levasseur, Desrosiers \& Noreau 2004) och kan utgöra en resurs för de äldre vid olika utmaningar i livet och i att anpassa sig till förändringar (Windsor, Hunter \& Browne-Yung 2015). Social delaktighet kan även förebygga utveckling av demens (Wang, Karp, Winblad \& Fratiglioni 2002). Utöver detta främjar social delaktighet och aktivitet individens känsla av meningsfullhet, förstärker det sociala nätverket (Glass 2009) och kan medverka till att upprätthålla fysisk hälsa, vilket i sin tur möjliggör deltagande och interaktion (Jolanki m.fl. 2017). Socialt deltagande har konstaterats vara högre bland kvinnor än bland män, medan man inte har funnit några könsskillnader beträffande känslan av samhörighet (Levasseur m.fl. 2017).

Socialt boende kan främja aktivitet och socialt deltagande genom att stärka invånarnas sociala nätverk; det är uttryckligen genom den sociala aspekten som socialt boende kan förbättra välbefinnande och livskvalitet (Tyvimaa 2011). Gemenskapen fungerar bl.a. som en källa till socialt och praktiskt stöd för invånarna. I en studie av Jolanki och Vilkko (2015) framkom att invånarna $\mathrm{i}$ seniorboenden upplevde att den ömsesidiga hjälpen och stödet var en viktig del av samhörighetskänslan i och med 
att man kände sig behövd. Känsla av samhörighet har även samband med känsla av likvärdighet, med möjlighet att lära sig av varandra och ett stärkt socialt kapital (Jolanki \& Vilkko 2015). Det har visat sig att social gemenskap stärker både det fysiska och det psykiska välbefinnandet (Jolanki m.fl. 2017) samt minskar depressiva symptom bland vuxna (Fowler, Wareham-Fowler \& Barnes 2013).

Det är möjligt att man genom att öka social verksamhet och invånarsamverkan kan förbättra välbefinnandet och livskvaliteten. En åldersvänlig miljö kan främja delaktighet genom att eliminera de fysiska och sociala murar eller hinder som gör att de äldre inte fullt ut kan delta i samhället (Scharlach \& Lehning 2013). Föreställningen om ett aktivt och socialt liv samt jämnårigt sällskap kan öka de äldres vilja att flytta till en social boendeform (Laurinkari m.fl. 2005; Tyvimaa \& Kemp 2011).

Man har tidigare forskat $\mathrm{i}$ hur aktivitet och socialitet står i samband med hälsa och välbefinnande bland äldre, men knappt alls bland dem som bor i seniorboende. Syftet med denna studie var att utreda sambanden mellan social gemenskap, socialt deltagande och aktivt åldrande bland äldre personer som bor i seniorboenden, samt dessa faktorers möjliga samband med hälsorelaterad livskvalitet och depressionssymptom. Utöver detta var syftet att framställa beskrivande information om hälsa och välbefinnande hos invånare i seniorboenden. Som datamaterial användes data insamlat i BoAktiv-studien bland personer som bor i Folkhälsans seniorbostäder.

\section{Forskningsmaterial och metoder}

Forskningen genomfördes som enkätundersökning. Målgruppen var personer över 55 år som bor självständigt i Folkhälsans seniorbostäder ( $n=465)$. Av dem svarade 194 (42\%) på enkäten. Data samlades in på 12 Folkhälsanhus som erbjuder seniorbostadservice. Dessa hus ligger i Helsingfors, Esbo, Vanda, Raseborg, Vasa,
Korsholm, Karleby, Pargas och Mariehamn. Det äldsta huset är från 1996 och ligger i Brunakärr i Helsingfors och de nyaste husen, som öppnades 2010, ligger i Esbo och Pargas. Nästan alla bostäder har säkerhetsalarmsystem, och husen erbjuder olika tjänster såsom måltidsservice samt hemtjänster, bland vilka invånarna på egen bekostnad kan välja lämpliga servicepaket för sin vardag. I flera kommuner är det möjligt att få servicesedlar för Folkhälsans tjänster. Husen har gemensamma utrymmen och lunchrestaurang, och största delen har bibliotek och gymnastiksal eller gym. Det är även möjligt att få hälsorådgivning av sjukskötare eller hälsovårdare. Folkhälsanhuset i Brunakärr har, förutom tidigare nämnda tjänster, övervakad morgonsimning, föreläsningssal, musiksal, mötesrum, frisör och fotvårdstjänster. I alla hus ordnas det även dagaktiviteter som gymnastik, yoga, sång- och musikevenemang, diskussioner och kaffestunder, fester, undervisning i teknik, bingo och bokcirklar, som är öppna för alla. De anställda i husen är till stor del vårdpersonal och ofta finns det också en servicekoordinator.

Datamaterialet samlades in under våren 2018, då forskningsgruppen besökte de 12 husen. Före besöket fanns det information om forskningen i de interna tidningarna och på husens anslagstavlor. Invånarna fick även en informationsblankett med inbjudan till ett informationstillfälle, där frågeformulären delades ut. Formulären kunde man antingen fylla i på plats eller ta med sig hem. De invånare som deltog $\mathrm{i}$ informationen kunde vid behov få hjälp att fylla i enkäten av forskningspersonalen. De övriga invånarna fick enkäten utdelad till hemmet. Svarstiden var två veckor.

Social gemenskap utreddes genom Sense of Community Index 2-mätaren (SCI-2) (Chavis, Lee \& Agosta 2008) samt frågor angående deltagande $\mathrm{i}$ aktiviteter som ordnas i huset. SCI-2 innefattar 24 påståenden om gemenskap, med en 4-gradig svarsskala. Respondenten bedömer i hur hög grad påståenden stämmer överens med hur hen upplever sin gemenskap, till exempel: "Jag kan på- 
verka hurdan denna gemenskap är" eller "Att passa in i denna gemenskap är viktigt för mig". Svarsalternativen är: 1) Stämmer inte alls, 2) Stämmer delvis, 3) Stämmer till en stor del och 4) Stämmer precis. Ett SCI-2 index skapades genom att räkna ut ett medeltal för svaren och därefter multiplicera talet med det totala antalet frågor. Poängsättningen är 0-3 poäng per svarsalternativ, vilket betyder att minimipoängen är 0 och maximum 72. Analysen exkluderade de blanketter $(n=41)$, som saknade svar på fler än sex frågor (>25\%). Variationsbredden i denna studie var 0-66 poäng. Ju högre poängantal desto högre var respondentens känsla av samhörighet.

Socialt deltagande mättes med hjälp av 8 olika aktiviteter som ordnas i huset. Vi frågade ifall invånaren deltar i följande evenemang: föreläsningar och diskussioner, olika uppträdanden, IT-hjälp, gemensamt program med daghem och skolor, besök av försäljare eller något annat program. Svarsalternativen var ja eller nej. Dessutom frågade vi hur ofta invånarna deltar i fester, motionsverksamhet och hobbyverksamhet. Svarsalternativen var: 1) dagligen, 2) flera gånger i veckan, 3) varje vecka, 4) sällan och 5) jag deltar inte. Svarsalternativen kodades om till dikotoma ja/nej alternativ genom att kombinera alternativen 1-4 och lämna svarsalternativ 5 i en egen kategori. Alla de tidigare nämnda svaren angående deltagande summerades till ett totalpoäng, där ett nejsvar gav 0 poäng medan ett ja-svar gav 1 poäng. Poängens variationsbredd var $0-8$ poäng. Ett högre antal poäng betyder att invånaren deltog i flera olika aktiviteter, medan ett litet poängantal betyder att invånaren deltog i endast ett fåtal eller inga aktiviteter alls.

Aktivt åldrande mättes med Jyväskylä universitets skala för aktivt åldrande (UJACAS) (Rantanen m.fl. 2018) som är ett nytt instrument för mätning på individnivå. Mätarens syfte är att beskriva hur äldre personer tar initiativ till aktiviteter (Rantanen m. fl. 2018). Med hjälp av frågorna i UJACAS instrumentet bedöms människans olika aktiviteter på fyra olika sätt: Mål (vilja till funktion), funktionsförmåga (abilitet till funktion), autonomi (möjlighet till funktion) och aktivitet (funktionens mängd och frekvens). Totalpoäng skapades genom att räkna ut ett medeltal för svaren och därefter multiplicera talet med det totala antalet frågor. Ju aktivare respondenten var, desto högre var poängantalet. Mätarens totalpoäng växlade mellan 10 och 260 poäng. Vi exkluderade de blanketter som saknade fler än två svar per delområde, och hela formuläret fick sakna högst åtta svar.

Hälsa och funktionsförmåga mättes med RAND-36 mätaren (Hayes, Sherbourne \& Mazel 1993; Aalto, Aro \& Teperi 1999) samt frågor om sjukdomar. Frågorna om sjukdomar grundade sig på Charlson comorbidity index (Charlson, Pompei, Ales \& MacKenzie 1987), och i formuläret fanns uppräknat 22 olika sjukdomar eller skador med ett ja eller nej svarsalternativ. RAND-36 mätarens frågor grupperades i åtta hälsodomäner: allmän hälsoupplevelse, fysisk funktion, fysisk rollfunktion, kroppslig smärta, vitalitet, social funktion, emotionell rollfunktion och psykiskt välbefinnande. Ett större antal poäng i de olika domänerna tyder på bättre funktionsförmåga.

Depressionssymptom mättes genom Center for Epidemiologic Studies Depression Scale (CES-D) - frågebatteriet (Radloff 1977).

Respondentens ålder beräknades från det angivna födelseåret, och kön definierades på basis av information från samtyckesblanketten. Utbildningsnivån mättes genom att be respondenten ange den högsta grad av utbildning som avlagts.

De resultat som vi rapporterar i denna artikel ger grundinformation för fortsatta analyser och uppföljning. Samband mellan aktivt åldrande, social gemenskap och social deltagande analyserades genom partiell korrelation. Analyserna kontrollerades för ålder, kön och utbildning. Urvalets åldersfördelning var stor, och några av analyserna gjordes skilt för dem under 80 år och dem som var 80 år eller äldre, då det kan finnas märkbara skillnader i funk- 
tionsförmågan mellan yngre och äldre seniorer (Smith m.fl. 2002). För att granska statistiska skillnader mellan åldersgrupperna användes t-test och variansanalys för de normalfördelade variablerna, och för de ej-normalfördelade variablerna Mann-Whitneys U-test. För de kategoriserade variablerna använde vi oss av $\chi 2$-testet. Gränsen för statistisk signifikans var $\mathrm{p}<0,05$. De statistiska analyserna genomfördes med programmet IBM SPSS Statistics 25.

\section{Resultat}

Basinformation om respondenterna presenteras i tabell 1. Medelåldern för hela samplet var 84 år, varav $26 \%$ var under 80 år och $74 \%$ minst 80 år. Kvinnor utgjorde $82 \%$ av respondenterna under 80 år, medan motsvarande tal bland dem som fyllt 80 år var $73 \%$. Majoriteten (nästan $90 \%$ ) hade svenska som modersmål. Mer än $42 \%$ av under 80-åringarna hade en högskoleutbildning medan motsvarande tal bland dem som redan fyllt 80 år var en tredjedel. De respondenter som var under 80 år hade bott i ett Folkhälsanhus i genomsnitt 5 år medan de 80-åriga eller äldre hade gjort det i 7 år. Respondenterna i den äldre åldersgruppen var oftare änkor eller änklingar och hade fler sjukdomar än den yngre gruppen. Hörselskador förekom hos den äldre gruppen betydligt mer än i den yngre. Av alla respondenter visade sig cirka hälften ha symptom på depression (44\%). Symptom på depression förekom hos $42 \%$ av dem under 80 år och cirka hälften av alla dem som fyllt 80 år. Hälsorelaterad livskvalitet (health-related quality of life) var sämre i den äldre respondentgruppen på nästan alla RAND-36 hälsodomäner förutom fysiskt rollbeteende och upplevd smärta (Tabell 1). Trefjärdedelar av respondenterna deltog i husens motionsverksamhet och $70 \%$ i annan hobbyverksamhet. Nästan alla (95\%) respondenter deltog i de fester och högtidsfestligheter som organiserades i husen, såsom grillkvällar och julfester.
Aktivt åldrande granskades med hjälp av UJACAS-mätarens fyra delområden samt totalpoängen. Respondenterna under 80 år upplevde att de hade bättre möjligheter till aktiviteter och de utförde mera aktiviteter jämfört med den äldre respondentgruppen (tabell 2). Det fanns ingen statistisk skillnad mellan åldersgrupperna i viljan och förmågan att vara aktiv, men totalpoängantalet var högre bland respondenter under 80 år. Korrelationen mellan skalan för aktivt åldrande och depressionssymtom var negativ medan det fanns en positiv korrelation mellan aktivt åldrande och alla RAND-36 delområden förutom emotionell rollfunktion och smärta (tabell 3). De äldre som var mera aktiva hade alltså en bättre hälsorelaterad livskvalitet och färre symptom på depression.

Det fanns ingen statistisk skillnad i poängen för social gemenskap (känsla av samhörighet) mellan åldersgrupperna. Bland dem som var yngre än 80 år var medeltalet 35,6 medan de som var 80 år eller äldre hade ett medeltal på 36 (tabell 2). För största delen (84 \%) var det viktigt att i alla fall i någon mån känna samhörighet med de andra invånarna i huset. Vi fann en positiv korrelation mellan känsla av samhörighet och psykisk hälsa samt vitalitet. Dessutom fanns en negativ korrelation mellan känsla av samhörighet och depressionssymtom (tabell 3). Ju högre känsla av samhörighet desto bättre var invånarnas psykiska hälsa, desto piggare och mer energiska var invånarna och desto mindre förekom det depressionssymtom.

Socialt deltagande skiljde sig inte mellan de två åldersgrupperna. De yngre respondenterna deltog i genomsnitt i 5,4 olika aktiviteter medan det motsvarande talet för äldre var 5,2 (tabell 2). Socialt deltagande korrelerade positivt med den mentala hälsan (tabell 3). Ju mera invånarna deltog i de olika aktiviteterna, desto bättre var deras mentala hälsa. Socialt deltagande korrelerade dessutom negativt med den fysiska rollfunktionen, med andra ord, ju mera invånarna deltog i de olika aktiviteterna, desto 
Tabell 1. Respondenternas basinformation enligt åldersgrupp

\begin{tabular}{|c|c|c|c|c|c|}
\hline & \multicolumn{2}{|c|}{$\begin{array}{l}\text { Under } 80 \text { år } \\
(n=48-51)\end{array}$} & \multicolumn{2}{|c|}{$\begin{array}{l}80 \text { år och äldre } \\
(n=121-142)\end{array}$} & \multirow[b]{2}{*}{ p-värde* } \\
\hline & $\%$ & $\mathrm{~m} . \mathrm{t} \pm \mathrm{st}$ & $\%$ & m.t \pm st. & \\
\hline Ålder & & $73,7 \pm 4,7$ & & $87,6 \pm 4,5$ & $<.001$ \\
\hline Kvinna & 82,4 & & 73,4 & & \\
\hline Modersmål & & & & & .322 \\
\hline Svenska & 88,2 & & 89,3 & & \\
\hline Finska & 7,8 & & 10,0 & & \\
\hline Annat & 4,0 & & 0,7 & & \\
\hline \multicolumn{6}{|l|}{ Utbildning } \\
\hline Mindre än folkskola & 0,0 & & 1,4 & & .183 \\
\hline Minst folkskola & 8,0 & & 21,6 & & \\
\hline Minst mellanskola & 32,0 & & 28,1 & & \\
\hline Minst studentexamen & 18,0 & & 18,7 & & \\
\hline Högskola/ universitetsexamen & 42,0 & & 30,2 & & \\
\hline Civilstånd & & & & & $<.001$ \\
\hline Gift, samboende & 23,5 & & 25,7 & & \\
\hline Ogift & 23,5 & & 3,6 & & \\
\hline Separerad eller frånskild & 25,5 & & 7,9 & & \\
\hline Änka/Änkling & 27,5 & & 62,9 & & \\
\hline Antalet år i Folkhälsanhus & & $4,7 \pm 4,1$ & & $6,8 \pm 5,1$ & .006 \\
\hline Fyllde i blanketten själv & 86,3 & & 72,8 & & .152 \\
\hline Antal sjukdomar & & $2,6 \pm 2,2$ & & $3,7 \pm 2,2$ & .003 \\
\hline Förhöjt blodtryck, blodtryckssjuk. & 58,0 & & 52,9 & & .620 \\
\hline Rytmstörningar i hjärtat & 28,0 & & 21,4 & & .337 \\
\hline Artros, slitage av led & 26,0 & & 35,0 & & .293 \\
\hline Synskada & 22,0 & & 40,0 & & .025 \\
\hline Hörselskada & 4,0 & & 37,9 & & $<.001$ \\
\hline CES-D poäng & & $13,8 \pm 8,8$ & & $16,6 \pm 8,8$ & $.064^{1}$ \\
\hline Depressionssymtom (CES-D $\geq 16 p$ ) & 42,0 & & 50,8 & & .319 \\
\hline \multicolumn{6}{|l|}{ RAND-36 } \\
\hline Fysisk funktion & & $67,3 \pm 29,1$ & & $52,6 \pm 24,8$ & $<.001$ \\
\hline Fysisk rollfunktion & & $56,6 \pm 42,3$ & & $44,8 \pm 42,1$ & .090 \\
\hline Smärta & & $63,0 \pm 26,5$ & & $62,1 \pm 27,7$ & .896 \\
\hline Allmän hälsa & & $61,1 \pm 19,9$ & & $54,4 \pm 19,4$ & .032 \\
\hline Mental hälsa & & $76,9 \pm 16,2$ & & $70,5 \pm 19,3$ & .049 \\
\hline Emotionell rollfunktion & & $78,1 \pm 34,2$ & & $60,8 \pm 43,8$ & .023 \\
\hline Social funktion & & $81,5 \pm 21,3$ & & $70,5 \pm 26,9$ & .012 \\
\hline Vitalitet & & $63,7 \pm 17,1$ & & $53,4 \pm 21,2$ & .004 \\
\hline Röker & 0,0 & & 0,7 & & .726 \\
\hline Fysisk aktivitet & & & & & .129 \\
\hline Lätt & 42,0 & & 54,6 & & \\
\hline Måttlig & 54,0 & & 44,7 & & \\
\hline Hård & 4,0 & & 0,8 & & \\
\hline Alkohol användning & & & & & .158 \\
\hline Varje vecka & 38,0 & & 25,5 & & \\
\hline Varje månad eller mindre & 32,0 & & 46,0 & & \\
\hline Använder inte & 30,0 & & 28,5 & & \\
\hline
\end{tabular}

*Mann-Whitney U -test för kontinuerliga variabler, korstabellering och $\chi 2$-test eller Fishers test för kategoriserade variabler. ${ }^{1}$ T-test. Obs. $m$.t. $=$ medeltal, st. $=$ standardavvikelse, $C E S-D=$ the Center for Epidemiologic Studies Depression Scale, RAND-36= Short form (36) health survey utdelat av RAND bolag. 
Tabell 2. Variansanalys (ANCOVA) om skillnader i social gemenskap (SCl-2), socialt deltagande och aktivt åldrande (UJACAS) mellan åldersgrupperna. Kontrollerat för kön och utbildning.

\begin{tabular}{lll|lll} 
& \multicolumn{2}{l}{ Under 80 år $(n=45-47)$} & \multicolumn{3}{c}{ Har fyllt 80 år (n=88-95) } \\
& m.t & $95 \%$ KI & m.t & $95 \%$ KI & p-värde \\
\hline Social gemenskap & 35,6 & $31,3-40,0$ & 36,0 & $33,1-38,8$ & .872 \\
Socialt deltagande & 5,4 & $4,6-6,2$ & 5,2 & $4,5-5,9$ & .498 \\
Aktivt åldrande & & & & & \\
$\quad$ Vilja till aktivitet & 46,2 & $42,0-50,4$ & 42,8 & $39,8-45,8$ & .142 \\
$\quad$ Förmåga till aktivitet & 53,1 & $48,1-58,0$ & 49,0 & $45,5-52,4$ & .131 \\
$\quad$ Möjlighet till aktivitet & 47,4 & $42,9-52,0$ & 40,9 & $37,7-44,1$ & .009 \\
$\quad$ Aktivitetsmängden/frekvens & 38,0 & $34,1-41,9$ & 33,4 & $30,6-36,2$ & .031 \\
$\quad$ Totalt & 185,4 & $170,0-201,0$ & 164,4 & $153,2-175,6$ & .015 \\
\hline
\end{tabular}

Tabell 3. Partiell korrelation mellan hälsorelaterad livskvalitet, depressionssymptom samt aktivt åldrande, social gemenskap och socialt deltagande. Kontrollerat för ålder, kön och utbildning.

\begin{tabular}{|c|c|c|c|}
\hline & Aktivt åldrande & Social gemenskap & Socialt deltagande \\
\hline Depression symtom & $-0,385 * * *$ & $-0,273 * *$ & $-0,165$ \\
\hline \multicolumn{4}{|l|}{ RAND-36 } \\
\hline Fysisk funktion & $0,526 * * *$ & 0,077 & $-0,059$ \\
\hline Fysisk rollfunktion & $0,205^{*}$ & $-0,131$ & $-0.207^{*}$ \\
\hline Smärta & 0,149 & 0,091 & $-0,073$ \\
\hline Allmän hälsa & $0,384 * * *$ & $-0,012$ & $-0,038$ \\
\hline Mental hälsa & $0,353^{* * *}$ & $0,326 * *$ & $0,255^{* *}$ \\
\hline Emotionell rollfunktion & 0,115 & 0,049 & 0,008 \\
\hline Social funktion & $0,294 * *$ & 0,060 & $-0,019$ \\
\hline Vitalitet & $0,398 * * *$ & $0,249 *$ & 0,183 \\
\hline
\end{tabular}

Tabell 4. Partiell korrelation mellan aktivt åldrande, social gemenskap och socialt deltagande. Kontrollerat för ålder, kön och utbildning.

\begin{tabular}{llll}
\hline Variabel & Aktivt åldrande & Social gemenskap & Socialt deltagande \\
\hline Aktivt åldrande & 1 & & \\
Social gemenskap &, $306^{* *}$ & 1 & 1 \\
Socialt deltagande &, $250^{*}$ &, $514^{* *}$ & 1 \\
\hline
\end{tabular}

*p-värde <0.01 **p-värde <0.001 
mer rapporterade de begränsningar på grund av fysiska hälsoproblem inom vardagliga aktiviteter/vardaglig rollfunktion.

I tabell 4 presenteras sambanden mellan aktivt åldrande, social gemenskap (känsla av samhörighet) och socialt deltagande. Aktivt åldrande korrelerade positivt med social gemenskap och hur aktivt man deltog i husets olika program. Ju högre poäng i aktivt åldrande desto starkare var personens känsla av samhörighet och desto mer deltog personen i husets aktiviteter.

\section{Diskussion}

Syftet med denna forskning var i första hand att granska sambanden mellan social gemenskap, socialt deltagande och aktivt åldrande bland invånare i seniorhus. Dessutom var vi intresserade av dessa faktorers möjliga samband med hälsorelaterad livskvalitet och depressionssymptom. Att åldras som aktiv hade samband med deltagandet i husens verksamhet samt med känslan av samhörighet. Aktiva äldre deltog alltså mera i seniorhusens verksamhet och upplevde mera samhörighet. Det går ändå inte att dra säkra slutsatser om kausaliteten då forskningen är en tvärsnittsstudie, men en känsla av samhörighet uppstår troligen inte så lätt, ifall man inte deltar i gemensamma aktiviteter eller är generellt aktiv. På basis av resultaten kan man ändå konstatera att bland invånare i seniorhus har aktivt åldrande, social gemenskap och socialt deltagande ett samband med varandra. Liknande forskning har gjorts bland personer som bor hemma, medan det endast finns ett fåtal motsvarande studier genomförda i seniorboenden.

Forskningsresultaten motsvarar resultat från tidigare forskning. Att samhörighet och socialt deltagande, eller till exempel gemensam sysselsättning, har ett samband med varandra, har konstaterats även i andra studier (Levasseur m.fl. 2017; Jolanki \& Vilkko 2015). Liksom i föreliggande studie har man i tidigare forsk- ning funnit samband mellan social gemenskap och depressionssymptom. Man har också funnit att gemenskap minskar symptom på depression (Fowler m.fl. 2013) och bl.a.på detta sätt stöder mentalt välbefinnande. Mätaren för aktivt åldrande har tidigare använts endast i forskning vid Jyväskylä universitet (Rantanen m.fl. 2018). I den studien var deltagarna, med ett snittpoäng på 200, mera aktiva än i vår studie, där totalpoängen i snitt var 188 även bland de yngre deltagarna. Deltagarna i Rantanens forskning var dock både yngre och bodde hemma. Vi fann att aktivt åldrande har ett positivt samband med upplevd hälsa, vilket stöder tidigare forskning (t.ex. von Bonsdorff \& Rantanen 2011; Di Gessa \& Grundy 2014). Hälsa i sig är en viktig faktor för utövandet av aktiviteter, och de aktivaste åldringarna är förmodligen även socialt aktiva, vilket i sin tur kan minska symptom på depression. Det negativa sambandet mellan socialt deltagande och fysisk rollfunktion kan förklaras med att oberoende av den nedsatta fysiska funktionsförmågan deltar invånarna aktivt i de olika evenemang och aktiviteter som ordnas i huset. Däremot vet vi inte hur ofta respondenterna deltar, vilket gör att även de mest funktionsnedsatta har kunnat svara att de deltagit även en gång $\mathrm{i}$ någon av husets aktiviteter. På basis av tidigare forskning kan man konstatera att det ordnas mycket social verksamhet $\mathrm{i}$ seniorhusen och invånarna deltar aktivt i verksamheten (Laurinkari m.f. 2005; Pedersen 2015). Även i denna studie deltog majoriteten av respondenterna i den verksamhet som organiserades i husen. Det är ändå oklart i hur stor mån de invånare som inte svarade på enkäten tar del i husets program.

Respondenterna i studien var välutbildade. Enligt uppgifter från Statistikcentralen var år 2016 cirka $7 \%$ av kvinnorna och 13 $\%$ av männen i hela befolkningen över 70 år högskoleutbildade. Man har tidigare funnit att invånare $\mathrm{i}$ seniorboenden är högre utbildade och har bättre inkomster jämfört med majoriteten av befolkningen (Pedersen 2015; Glass 2009). Enligt tidigare forskning bor det 
vanligen fler kvinnor än män i seniorboenden (Choi 2004; Glass 2009; Tyvimaa 2011; Pedersen 2015; Lotvonen, Kyngäs, Koistinen, Bloigu \& Elo 2018), så också i vår studie. Seniorboende upplevs ofta vara ett tryggt boendealternativ och eventuellt söker sig ensamboende kvinnor lättare till denna slags boendeform. Att man vill förbereda sig för framtiden kan alltså vara en viktig orsak till att man flyttar till seniorboende. Könsfördelningen i de olika åldersgrupperna var aningen avvikande, då det vanligen finns en större andel kvinnor ju äldre grupp det är frågan om. I denna studie fanns det ändå procentuellt fler kvinnor i den yngre åldersgruppen jämfört med den äldre. Kvinnorna i den äldre åldersgruppen kan ha haft ett sämre hälsotillstånd än männen (Murtagh \& Hubert 2004) och därmed lämnat enkäten obesvarad. Även sampelstorleken kan ha inverkat. Oberoende av ålder hade en stor del av respondenterna symptom på depression. Enligt tidigare forskning är depressionssymtom relativt vanliga bland åldringar (t.ex. Lotvonen m.fl. 2018; Glaesmer, RiedelHeller, Braehler, Spangenberg \& Luppa 2011). Med stigande ålder försämras även hälsorelaterad livskvalitet (Aalto m.fl. 1999), vilket också vi fann i denna studie: de äldre respondenterna hade sämre hälsorelaterad livskvalitet jämfört med den yngre åldersgruppen.

Forskningens sampel var ändå relativt litet och minskade ytterligare då vi lämnade bort respondenter som inte hade svarat på tillräckligt många delfrågor i de olika mätarna, t.ex. SCI-2. Samplets storlek begränsade en samtidig stratifiering i ålder och kön, och vi gjorde därmed inte jämförande analyser mellan kvinnor och män. Enkätens längd kan ha gallrat bort en del respondenter, även om svarstiden torde ha varit tillräcklig. Majoriteten av respondenterna var över 80 år, men kunde fylla i enkäten självständigt utan hjälp, vilket innebär att det till stor del var respondenter med relativt gott hälsotillstånd som besvarade enkäten. De svagaste invånarna lät förmodligen bli att svara på eller att returnera enkäten, vilket betyder att man inte kan dra några generella slutsatser.

Då man tar hänsyn till svarsprocenten, den höga utbildningsnivån samt hälsotillståndet hos respondenterna så kan man konstatera att populationen är relativt utvald. Respondenternas utbildningsnivå var påfallande hög, vilket betyder att resultaten inte kan tillämpas direkt på hela befolkningen i samma ålder, eftersom högre utbildade har allmänt bättre hälsa och de svarar mer aktivt på enkäter jämfört med lägre utbildade (t.ex. Tolonen m.fl. 2006). Dessutom var majoriteten av deltagarna svenskspråkiga, vilket gör att det inte går att generalisera resultaten till resten av befolkningen, där största delen är finskspråkig. Det är möjligt att den finskspråkiga äldre populationen skiljer sig hälsomässigt från den svenskspråkiga, då den svenskspråkiga befolkningen har visat sig ha lägre risk för tidig dödlighet (Koskinen \& Martelin 2003) och större sannolikhet att leva friska och aktiva längre (Hyyppä \& Mäki 2001). Man har föreslagit att skillnaderna beror på ett högre socialt kapital bland den svenskspråkiga befolkningen (Hyyppä \& Mäki 2001), men även på levnadsvanorna. Den svenskspråkiga populationen rapporterar t.ex. lägre grad av berusningsdrickande och därmed även mindre av dess följder (Paljärvi, Suominen, Koskenvuo, Winter \& Kauhanen 2009). Framöver kommer vi att göra jämförelser med den finskspråkiga befolkningen som bor i seniorboenden i syfte att granska eventuella skillnader mellan språkgrupperna i aktivitet och social gemenskap, speciellt skillnader i hälsovariabler som kan bero på socialt kapital.

I seniorboenden är det viktigt att sträva till att öka möjligheterna för invånarna att vara aktiva och socialt deltagande - speciellt då det gäller de äldre invånarna - vilket kan öka social gemenskap. Med hjälp av dylika åtgärder kan man förbättra det allmänna välbefinnandet bland de äldre, bl.a. genom att depressionssymptomen sannolikt minskar. Man kunde gärna involvera seniorerna mera i planeringen 
av gemensam verksamhet, och verksamheten borde dessutom organiseras närbeläget och lättillgängligt; då funktionsförmågan försämras är tillgänglighet en förutsättning för samhörighet (Jolanki, Topo, Rappe \& Teittinen 2017). Det är relativt enkelt att organisera denna slags verksamhet i seniorhus, i och med att det är lätt för invånarna att ta sig till platsen. Detta görs de facto redan i flera seniorhus och även i dag-

\section{Litteratur}

Aalto, A., Aro, A. \& Teperi, J. (1999). RAND-36 terveyteen liittyvän elämänlaadun mittarina. Mittarin luotettavuus ja suomalaiset väestöarvot. Stakes, Sosiaali- ja terveysalan tutkimus- ja kehittämiskeskus, Tutkimuksia 101. Hämtad 19.6.2018 från http://www.thl.fi/toimia/tietokanta/media/files/ mittariversio/2013/04/04/RAND-36_ohjeet_ Aalto_1999.pdf.

Charlson, M., Pompei, P., Ales, K. \& MacKenzie, C. (1987). A new method of classifying prognostic comorbidity in longitudinal studies: development and validation. Journal of Chronic Diseases, 40(5), 373-383. doi:10.1016/0021-9681(87)90171-8.

Chavis, D., Lee, K. \& Acosta J. (2008). The Sense of Community (SCI) Revised: The Reliability and Validity of the SCI-2. Paper presented at the 2nd International Community Psychology Conference, Lisboa, Portugal. Hämtad 27.6.2018 från https://www.slideshare.net/jonathandunnemann/sense-of-community-index-2sci2.

Choi, J. (2004). Evaluation of community planning and life of senior cohousing projects in Northern European countries. European Planning Studies, 12(8), 1189-1216. doi:10.1080/0965431042000289296.

Di Gessa, G. \& Grundy, E. (2014). The relationship between active ageing and health using longitudinal data from Denmark, France, Italy and England. Journal of Epidemiology \& Community Health, 68(3), 261-267.

doi:10.1136/jech-2013-202820.

Fowler, K., Wareham-Fowler, S., \& Barnes, C. (2013). Social context and depression severity and $\mathrm{du}-$ ration in Canadian men and women: exploring the influence of social support and sense of community belongingness. Journal of Applied Social Psychology, 43, E85-E96. doi:10.1111/jasp.12050. verksamhet för äldre. Det finns alltså utmärkta möjligheter att stöda de äldres välmående mångsidigt i seniorhus.

\section{Kontakt:}

Anna-Maria Lahti, HVM, projektkoordinator Folkhälsans forskningscentrum anna.1ahti@folkhalsan.fi

Glaesmer, H., Riedel-Heller, S., Braehler, E., Spangenberg, L. \& Luppa, M. (2011). Age-and gender-specific prevalence and risk factors for depressive symptoms in the elderly: a population-based study. International psychogeriatrics, 23(8), 12941300. doi:10.1017/S1041610211000780.

Glass, A. (2009). Aging in a community of mutual support: The emergence of an elder intentional cohousing community in the United States. Journal of Housing for the Elderly, 23(4), 283-303. doi:10.1080/02763890903326970.

Hayes, R., Sherbourne, C. \& Mazel, R. (1993). The RAND 36-item Health Survey 1.0. Health Economics, 2, 217-227. doi:10.1002/hec. 4730020305 .

Hyyppä, M. \& Mäki, J. (2001). Why do Swedish-speaking Finns have longer active life? An area for social capital research. Health Promotion International, 16(1), 55-64. doi:10.1093/heapro/16.1.55.

Jolanki, O. \& Vilkko, A. (2015). The meaning of a "sense of community" in a Finnish senior co-housing community. Journal of Housing for the Elderly, 29(1-2), 111-125. doi:10.1080/02763893.2015.989767.

Jolanki, O., Leinonen, E., Rajaniemi, J., Rappe, E., Räsänen, T., Teittinen, O. \& Topo, P. (2017). Asumisen yhteisöllisyys ja hyvä vanhuus. Valtioneuvoston selvitys- ja tutkimustoiminnan julkaisusarja 47/2017. Valtioneuvoston kanslia. Hämtad 10.6.2018 från http://tietokayttoon.fi/ documents/10616/3866814/47_ASUVA-loppuraportti+2017_NETTI.indd.pdf/81ebc84d-3636-4314-a2d5-a223b38d30d4?version $=1.0$.

Jolanki, O., Topo, P., Rappe, J. \& Teittinen, O. (2017). Asumisen ybteisöllisyydestä hyvinvointia iäkkäälle. Valtioneuvoston selvitys- ja tutkimustoimin- 
nan policy brief 9/2017. Valtioneuvoston kanslia. Hämtad 24.1.2019 från https://tietokayttoon.fi/ documents/1927382/2116852/9_2017_Asumisen+yhteis $\% \mathrm{C} 3 \% \mathrm{~B} 61$ lisyydest $\% \mathrm{C} 3 \% \mathrm{~A} 4+$ hyvinvointia+i\%C $3 \% \mathrm{~A} 4 \mathrm{kk} \% \mathrm{C} 3 \% \mathrm{~A} 4 \% \mathrm{C} 3 \% \mathrm{~A} 4$ $11 \mathrm{e} / 535 \mathrm{c} 56 \mathrm{~d} 8$-cdd $9-4 \mathrm{~d} 83-\mathrm{b} 981-\mathrm{fd} 15 \mathrm{cbc}-$ $53 \mathrm{c} 65$ ?version $=1.0$.

Koskinen, S. \& Martelin, T. (2003). Why is mortality low among the Swedish-speaking minority in Finland? Finnish Yearbook of Population Research, 15-31.

Lag om stödjande av den äldre befolkningens funktionsförmåga och om social- och hälsovårdstjänster för äldre. 28.12.2012/980. Hämtad 22.11.2018 från https://www.finlex.fi/fi/laki/ ajantasa/2012/20120980.

Laurinkari, J., Poutanen, V., Saarinen, A. \& Laukkanen, T. (2005). Senioritalo ikääntyneen asumisvaihtoehtona. Kysely-ja haastattelututkimus Joensuussa, Kuopiossa ja Tampereella vuonna 2005. Suomen Ympäristö 815. Hämtad 16.11.2017 från https://helda.helsinki.fi/bitstream/handle/10138/40550/SY_815.pdf?sequence $=1$.

Levasseur, M., Desrosiers, J. \& Noreau, L. (2004). Is social participation associated with quality of life of older adults with physical disabilities? Disability and rebabilitation, 26(20), 1206-1213. doi:10.1080/09638280412331270371.

Levasseur, M., Roy, M., Michallet, B., St-Hilaire, F., Maltais, D. \& Généreux, M. (2017). Associations between Resilience, Community Belonging, and Social Participation among Community-Dwelling Older Adults: Results from the Eastern Townships Population Health Survey. Archives of physical medicine and rehabilitation, 98(12), 24222432. doi:10.1016/j.apmr.2017.03.025.

Lotvonen, S., Kyngäs, H., Koistinen, P., Bloigu, R. \& Elo, S. (2018). Mental well-being of older people in Finland during the first year in senior housing and its association with physical performance. International journal of Environmental Research and Public Health, 15(7), 1331. doi:10.3390/ ijerph15071331.

Mikkola, K. \& Rasila H. (2006). Senioriasuminen Suomessa ja ulkomailla. I Tuppurainen, Y. (red.) Tulevaisuuden senioriasuminen (TSA) -hanke. Loppuraportti. Oulun yliopisto, julkaisu AO/A37. Oulu: Oulun yliopistopaino. Hämtad 24.1.2019 från

http://jultika.oulu.fi/files/isbn9514281594.pdf.
Miljöministeriet (2013). Ikääntyneiden asumisen kehittämisohjelma vuosille 2013-2017. Valtioneuvoston periaatepäätös 18.4.2013. Hämtad 24.1.2019 från

http://www.ym.fi/fi-FI/Asuminen/Ohjelmat_ ja_strategiat/Paattyneet_hankkeet/Ikaantyneiden_asumisen_kehittamisohjelma(1679).

Murtagh, K. \& Hubert, H. (2004). Gender differences in physical disability among an elderly cohort. American Journal of Public Health, 94(8), 14061411. Doi 10.2105/AJPH.94.8.1406.

Nathan, A., Wood, L. \& Giles-Corti, B. (2014). Exploring socioecological correlates of active living in retirement village residents. Journal of Aging $\mathcal{E}^{\circ}$ Physical Activity, 22(1), 1-15. doi:10.1123/japa.2012-0189.

Paljärvi, T., Suominen, S., Koskenvuo, M., Winter, T. \& Kauhanen, J. (2009). The differences in drinking patterns between Finnish-speaking majority and Swedish-speaking minority in Finland. European Journal of Public Health, 19(3), 278-284. doi:10.1093/eurpub/ckp007.

Pedersen, M. (2015). Senior co-housing communities in Denmark. Journal of Housing for the Elderly, 29(1-2), 126-145. doi:10.1080/02763893.2015.989770.

Radloff L.S. (1977). The CES-D scale: A self-report depression scale for research in the general population. Applied Psychological Measurement, 1(3), 385-401. doi:10.1177/014662167700100306.

Rantanen, T., Portegijs, E., Kokko, K., Rantakokko, M., Törmäkangas, T. \& Saajanaho, M. (2018). Developing an Assessment Method of Active Aging: University of Jyvaskyla Active Aging Scale. Journal of Aging and Health. doi:10.1177/0898264317750449.

Rossi, G., Boccacin, L., Bramanti, D. \& Meda, S. (2014). Active ageing: intergenerational relationships and social generativity. I G. Riva, P.A. Marsan \& C. Grassi Active Ageing and Healthy Living: A Human Centered Approach in Research and Innovation as Source of Quality of Life (s. 57-68). Amsterdam: IOS Press BV. doi:10.3233/978-1-61499-425-1-57.

Sainio, P., Stenholm, S., Valkeinen, H., Vaara, M., Heliövaara, M. \& Koskinen, S. (2012). Toiminta- ja työkyky. I P. Koponen, K. Borodulin, A. Lundqvist, K. Sääksjärvi ja S. Koskinen (red.). Terveys, toimintakyky ja hyvinvointi Suomessa - FinTerveys 2017 -tutkimus (s. 108-136). 
Raportti 4/2018 Helsinki: Terveyden ja hyvinvoinnin laitos. Helsinki 2012. http://urn.fi/URN:ISBN:978-952-343-105-8.

Scharlach, A. E. \& Lehning, A. J. (2013). Ageing-friendly communities and social inclusion in the United States of America. Ageing E Society, 33(1). doi:10.1017/S0144686X12000578.

Smith, J., Borchelt, M., Maier, H. \& Jopp, D. (2002). Health and well-being in the young old and oldest old. Journal of Social Issues, 58(4), 715-732. doi:10.1111/1540-4560.00286.

Sousa, N., Lima, M., Cesar, C., \& Barros, M. (2018). Active aging: prevalence and gender and age differences in a population-based study. Cadernos de saúde pública, 34(11). doi:10.1590/0102-311X00173317.

Statistikcentralen (2016). Naiset ja miehet Suomessa 2016. Hämtad 07.09.2018 från http://www.stat. fi/tup/julkaisut/tiedostot/julkaisuluettelo/yyti_ namisu_201600_2016_16132_net.pdf.

Tolonen, H., Helakorpi, S., Talala, K., Helasoja, V., Martelin, T., \& Prättälä, R. (2006). 25-year trends and socio-demographic differences in response rates: Finnish adult health behaviour survey. European Journal of Epidemiology, 21(6), 409415. Doi: 10.1007/s10654-006-9019-8.

Tyvimaa, T. \& Kemp, C. (2011). Finnish seniors' move to a senior house: Examining the push and pull factors. Journal of Housing for the Elderly, 25(1), 50-71. doi: 10.1080/02763893.2011.545742.

Tyvimaa, T. (2011). Social and physical environments in senior communities: The Finnish experience.
International Journal of Housing Markets and Analysis, 4(3), 197-209. doi:10.1108/17538271111152997.

Wang, H., Karp, A., Winblad, B. \& Fratiglioni, L. (2002). Late-life engagement in social and leisure activities is associated with a decreased risk of dementia: a longitudinal study from the Kungsholmen project. American Journal of Epidemiology, 155(12), 1081-1087. doi:10.1093/aje/155.12.1081.

Windsor, T., Hunter, M. \& Browne-Yung, K. (2015). Ageing well: building resilience in individuals and communities. Flinders Centre for Ageing Studies. Hämtad 12.09.2018 från http://www.sahealth.sa.gov.au/wps/wcm/connect/e35948004ac667418a67de0b65544981/ Ageing\%2BWell\%2BBuilding\%2BResilience\%2Bin\%2BIndividuals\%2Band\%2BCommunities.pdf?MOD=AJPERES\&CACHE $=$ NONE $\& C O N T E N T-$ $\mathrm{CACHE}=\mathrm{NONE}$.

Von Bonsdorff, M. B. \& Rantanen, T. (2011). Benefits of formal voluntary work among older people. A review. Aging Clinical and Experimental Research, 23(3), 162-169. doi: 10.3275/7200.

World Health Organization. (2002). Active aging: $A$ policy framewwork. Hämtad 22.9.2018 från http://apps.who.int/iris/bitstream/handle/10665/67215/WHO_NMH_ NPH_02.8.pdf;jsessionid=20BDEE1998CF5F87CD20095B6F251614?sequence $=1$. 